\title{
What's Coming Down the Pipe-And Should We Be Excited, Concerned, or Both?
}

$I^{\mathrm{n}}$ n the article entitled "Canadian Experience with the Pipeline Embolization Device for Repair of Unruptured Intracranial Aneurysms" in the current issue of AJNR, O'Kelly et $\mathrm{al}^{1}$ report on the combined experience of 7 Canadian centers between July 2008 and December 2010 using the Pipeline Embolization Device (PED; Covidien, Irvine, California), a flow-diverting stent, to treat unruptured intracranial aneurysms. During this period, the combined teams treated 97 unruptured aneurysms and followed the patients radiographically and clinically. This article retrospectively reviewed the collected data. Technique and follow-up were heterogeneous among the centers and not controlled for. Mean aneurysm size was $19 \mathrm{~mm}$, and mean aneurysm neck width was 8 $\mathrm{mm}$. Stents were successfully deployed in 94/97 lesions, and occlusion or near-occlusion of the aneurysm was noted in $84.2 \%$ at a mean of 1.25 years of follow-up and $90 \%$ at 1 year of follow-up. At follow-up, $89.3 \%$ of patients were clinically stable or improved. There were $4(4.3 \%)$ patients with a new neurologic deficit and 6 deaths $(6.4 \%$ mortality) in the series. There were 7 postoperative intracranial hemorrhages, 3 thought to be from the treated aneurysm and 4 distal and ipsilateral to the treated parent vessel. In the cavernous aneurysm cohort $(n=28)$, all lesions were noted to be completely or nearly completely occluded at follow-up and there were no serious neurologic complications, hemorrhages, or deaths associated with Pipeline stent placement in lesions in this location. The authors concluded that the Pipeline may represent an important part of the evolving endovascular technology but is associated, particularly for noncavernous lesions, with significant potential complications that must be considered.

The PED is a low-porosity endovascular stent designed to treat intracranial aneurysms by acting as a flow diverter. In other words, the stent attempts to reconstruct the parent vessel harboring aneurysms, diverting blood flow away from the aneurysm itself, resulting in intra-aneurysmal thrombosis, endoluminal scaffolding, and restoration of normal flow in the parent vessel. Further intended results include a remodeled vessel with the development of neointimal proliferation, which may lead to increased aneurysm obliteration and decreased recurrence. The device, which was granted FDA approval in 2011 and boasts 3-5 times increased surface coverage compared with other intracra- nial stents on the market, was designed for the treatment of wideneck large and giant saccular and fusiform aneurysms. Currently, FDA approval for use in the United States is strictly limited to the following criteria: age, $>22$ years; aneurysm neck, $>4 \mathrm{~mm}$; aneurysm size, $>10 \mathrm{~mm}$; and aneurysm location between the petrous and superior hypophyseal segments of the internal carotid artery. Absolute contraindications include patients with active bacterial infection, patients in whom dual antiplatelet therapy is contraindicated, patients who have not received dual antiplatelet agents before the procedure, and patients harboring a prior stent at the target aneurysm site.

The delivery requires a $6 \mathrm{~F}$ sheath and a guide catheter system. The stent itself is deployed via a 0.027 -inch microcatheter. The company recommends using a 0.014 - or 0.016 -inch wire. Stent deployment is accomplished via a slow unsheathing in conjunction with a push/pull and twisting motion that allows the stent to remodel the vessel as it is deployed. The deployment process is much slower than that with other intracranial stents, and resheathing is not possible. Premedication with dual antiplatelets and intraprocedural heparinization is recommended by the company, but this is left to the judgment of the individual therapist. Continuation of the antiplatelet regimen for at least 3 months is recommended, and serial radiographic follow-up is also necessary; however, poststenting imaging protocols have also not yet been established. Coding and billing of the implantation of the stent as an "embolization device" are similar to those for aneurysm coiling. In most instances, the stent (or multiple telescoping stents as is sometimes necessary) is adequate to achieve intraaneurysmal thrombosis, but concomitant coiling is feasible with a jailed catheter before stent deployment because the pores will not permit passage of a microcatheter.

In this commentary, I wish to explore 3 issues regarding the PED: 1) reviewing the regulatory data leading to the introduction of this new endovascular device on the market, 2) training and credentialing for this new device and how an individual user and hospital can access the device for their patients, and 3) addressing where this new device falls in terms of judicious clinical use.

FDA approval for the PED device was granted after submission of data from the Pipeline for Uncoilable or Failed Aneurysms 
(PUFS, unpublished) and the Pipeline Embolization Device for the Intracranial Treatment of Aneurysms (PITA) trials, ${ }^{2}$ in addition to nonhuman and other smaller human studies. In the PUFS trial, 108 patients underwent attempted PED placement to treat wide-neck unruptured large aneurysms along the carotid segment from the petrous to the paraclinoid region between 2008 and 2009. Technical success was achieved in 107/108 aneurysms (99\%). Of 364 PEDs used to treat these aneurysms, there was only 1 device failure. Ipsilateral major stroke or death occurred in 5.6\% of patients. There was 1 death due to a delayed aneurysm rupture on day 14. Angiography performed at 180 days postdeployment demonstrated complete aneurysmal occlusion with $<50 \%$ parent vessel stenosis in $73.6 \%$ of the studied cohort ( 99 subjects). In the PITA multicenter trial from Europe, 31 wide-neck unruptured aneurysms involving several different locations but, predominantly, the proximal internal intracranial carotid artery were treated with the PED. Mean aneurysm size was $11.5 \mathrm{~mm}$, and $38.7 \%$ of lesions had undergone prior endovascular treatment. Technical successful deployment was demonstrated in $96.8 \%$ of cases, with 6-month angiographic aneurysm occlusion in $93 \%$ of patients. Two patients had periprocedural major strokes $(6.5 \%)$, and there was no significant angiographic stenosis at 6 months.

There are currently no organizational credentialing standards for the placement of the PED, similar to neurointerventional training in general. The company, in conjunction with the FDA, has developed a set of criteria for clinical use, but the decision to allow an individual physician to place the PED lies squarely with the hospital administration once the criteria of the company are met. In the United States, to purchase and use the PED, the company mandates that any user attend a 1-day educational course, which includes hands-on PED deployment in a flow model. After that, the user must submit pictures on-line of intended cases meeting the previously described criteria selected by the manufacturing company: aneurysms measuring at least $10 \mathrm{~mm}$ in greatest dimension from the petrous to the superior hypophyseal location with wide necks measuring at least $4 \mathrm{~mm}$ in patients older than 22 years of age without any of the above-mentioned absolute contraindications. Cases are reviewed by a PED proctor hired by the company. If the adjudicator is satisfied that the case meets the criteria, the company coordinates a proctor to supervise the case. This process is the same for the first 5 cases for a given physician using the device. After those 5 cases, the next 5 cases, also meeting the above criteria, are attended by a nonphysician certified PED representative from the company. After those 10 cases are completed, the user may access the PED for use as he or she sees fit.

Since its rollout into the market, there has been a flurry of publications documenting use of the PED in myriad clinical situations, many off-label. ${ }^{3-24}$ Complication rates, aneurysm occlusion rates, and in-stent stenosis rates with both short and intermediate follow-up have all been described, often with rates inconsistent with those reported in the premarket approval trials and quite disparate from 1 publication to the next. ${ }^{8,21,25-32}$ This variability has not yet been accounted for. PED placement in patients harboring dissecting aneurysms, fusiform aneurysms, ruptured aneurysms, and saccular aneurysms of both the anterior and posterior circulation at sites other than the carotid petrous to superior hypophyseal internal carotid artery segments has been described. This use is not unexpected and reflects a somewhat disappointing and, I believe, backward way for new endovascular devices to be tested on humans. In the spirit of "I have a new device that is available to me and it might treat a lesion that I could not or would not otherwise treat," the PED has been used in a host of situations for which it did not garner FDA approval and for which there are precious few if any animal or human data to suggest safety or efficacy. Therefore, there is a very fine line between an operator believing that the natural history of the lesion untreated or treated with other available methods is so high that using a new device without a track record is justifiable and calling the treatment "assault and battery" of the patient. This subtle difference is not refereed by the company nor hospitals nor physicians themselves, and this inadequacy relates to the significance of "on-label" and "off-label" use, which is beyond the scope of this commentary. Be that as it may, we are left with a slew of everincreasing publications by those brave enough to share their adventures and perhaps pleased enough with their results. We are plunged into this new world with the hope that we can get a better handle on the actual risks, benefits, and alternatives to using the PED in a given individual and without having to wait for a valid trial or recreate the same costly mistakes.

One of the newer complications encountered with the PED at a much higher rate than for non-PED endovascular therapy for unruptured aneurysms is intracranial hemorrhage, both aneurys$\mathrm{mal}$ and distant from the treated lesion, amounting to $0 \%-11 \%$ in variously reported series. The etiology of this complication is currently unknown, but the consequences for these patients who are typically on dual antiplatelet therapy are often disastrous. This type of complication is particularly unsettling, given our uncertainty of the dangers of an unruptured aneurysm compared with its ruptured counterpart, even for large, giant, or irregular lesions. The article by O'Kelly et $\mathrm{al}^{1}$ is an important contribution to the literature in that it demonstrates that PED use for cavernous aneurysms carries a markedly lower rate of this dreaded complication; this article provides a good argument for using the PED for treating select cavernous lesions, which ironically already have a lower natural history. Noncavernous lesions, particularly lesions beyond the superior hypophyseal segment, should be treated with extreme caution and only after traditional approaches with better understood risk profiles have been exhausted and in cases in which there is a very strong probability that the risk of using the PED with its associated hemorrhage risk is lower than leaving the aneurysm alone. Unaddressed concerns regarding the use of PED include the following: duration of antiplatelet therapy, most appropriate imaging follow-up, cost-effectiveness relative to other potential treatment options, determination of the aneurysm, patient- or operator-specific factors that predispose these lesions to bleed posttreatment, long-term recurrence rate and in-stent stenosis rate, and when to complement stent placement with coiling.

\section{REFERENCES}

1. O'Kelly CJ, Spears J, Chow M, et al. Canadian experience with the Pipeline embolization device for repair of unruptured intracranial aneurysms. AJNR Am J Neuroradiol 2013;34:381-87

2. Nelson PK, Lylyk P, Szikora I, et al. The Pipeline embolization device for the intracranial treatment of aneurysms trial. AJNR Am J Neuroradiol 2011;32:34-40

AJNR Am J Neuroradiol 34:388-90 Feb 2013 www.ajnr.org 389 
3. Yu SC, Kwok CK, Cheng PW, et al. Intracranial aneurysms: midterm outcome of Pipeline embolization device-a prospective study in 143 patients with 178 aneurysms. Radiology 2012;265:893-901

4. Nyberg EM, Chaudry MI, Turk AS, et al. Novel use of the Pipeline embolization device for reperfusion of the middle cerebral artery post surgical aneurysm clipping. J Neurointerv Surg 2012 Jul 5. [Epub ahead of print]

5. Fiorella D, Kelly ME, Albuquerque FC, et al. Curative reconstruction of a giant midbasilar trunk aneurysm with the Pipeline embolization device. Neurosurgery 2009;64:212-17

6. Fiorella D, Albuquerque F, Gonzalez F, et al. Reconstruction of the right anterior circulation with the Pipeline embolization device to achieve treatment of a progressively symptomatic, large carotid aneurysm. J Neurointerv Surg 2010;2:31-37

7. Fiorella D, Woo $\mathrm{HH}$, Albuquerque FC, et al. Definitive reconstruction of circumferential, fusiform intracranial aneurysms with the Pipeline embolization device. Neurosurgery 2008;62:1120-21

8. Chitale R, Gonzalez LF, Randazzo C, et al. Single center experience with Pipeline stent: feasibility, technique, and complications. Neurosurgery 2012;71:679-91

9. Kadkhodayan Y, Shetty VS, Blackburn SL, et al. Pipeline embolization device and subsequent vessel sacrifice for treatment of a bleeding carotid pseudoaneurysm at the skull base: a case report. $J \mathrm{Neu}$ rointerv Surg 2012 Jul 28. [Epub ahead of print]

10. Lubicz B, Collignon L, Raphaeli G, et al. Pipeline flow-diverter stent for endovascular treatment of intracranial aneurysms: preliminary experience in 20 patients with 27 aneurysms. World Neurosurg 2011; 76:114-19

11. Kerl HU, Al-Zghloul M, Groden C, et al. Endovascular repositioning of a Pipeline embolization device dislocated from the vertebral into the basilar artery using a stent-in-stent technique: practical and technical considerations. Clin Neuroradiol 2012;22:47-54

12. Phillips TJ, Wenderoth JD, Phatouros CC, et al. Safety of the Pipeline embolization device in treatment of posterior circulation aneurysms. AJNR Am J Neuroradiol 2012;33:1225-31

13. de Barros Faria M, Castro RN, Lundquist J, et al. The role of the Pipeline embolization device for the treatment of dissecting intracranial aneurysms. AJNR Am J Neuroradiol 2011;32:2192-95

14. Chan TT, Chan KY, Pang PK, et al. Pipeline embolisation device for wide-necked internal carotid artery aneurysms in a hospital in Hong Kong: preliminary experience. Hong Kong Med J2011;17:398 404

15. Hauck EF, Natarajan SK, Langer DJ, et al. Retrograde trans-posterior communicating artery snare-assisted rescue of lost access to a foreshortened Pipeline embolization device: complication management. Neurosurgery 2010;67(2 suppl operative):495-502

16. Lylyk P, Miranda C, Ceratto R, et al. Curative endovascular reconstruction of cerebral aneurysms with the Pipeline embolization device: the Buenos Aires experience. Neurosurgery 2009;64:632-42

17. Szikora I, Berentei Z, Kulcsar Z, et al. Treatment of intracranial aneurysms by functional reconstruction of the parent artery: the $\mathrm{Bu}$ dapest experience with the Pipeline embolization device. AJNR Am J Neuroradiol 2010;31:1139-47

18. Yeung TW, Lai V, Lau HY, et al. Long-term outcome of endovascular reconstruction with the Pipeline embolization device in the man- agement of unruptured dissecting aneurysms of the intracranial vertebral artery. J Neurosurg 2012;116:882-87

19. Siddiqui AH, Abla AA, Kan P, et al. Panacea or problem: flow diverters in the treatment of symptomatic large or giant fusiform vertebrobasilar aneurysms. J Neurosurg 2012;116:1258-66

20. Puffer RC, Kallmes DF, Cloft HJ, et al. Patency of the ophthalmic artery after flow diversion treatment of paraclinoid aneurysms. J Neurosurg 2012;116:892-96

21. Deutschmann HA, Wehrschuetz M, Augustin M, et al. Long-term follow-up after treatment of intracranial aneurysms with the Pipeline embolization device: results from a single center. AJNR Am J Neuroradiol 2012;33:481-86

22. McAuliffe $\mathrm{W}, \mathrm{Wycoco} \mathrm{V}$, Rice $\mathrm{H}$, et al. Immediate and midterm results following treatment of unruptured intracranial aneurysms with the Pipeline embolization device. AJNR Am J Neuroradiol 2012; 33: $164-70$

23. Martin AR, Cruz JP, Matouk CC, et al. The Pipeline flow-diverting stent for exclusion of ruptured intracranial aneurysms with difficult morphologies. Neurosurgery 2012;70:21-28

24. Narata AP, Yilmaz H, Schaller K, et al. Flow-diverting stent for ruptured intracranial dissecting aneurysm of vertebral artery. Neurosurgery 2012;70:982-88

25. Velat GJ, Fargen KM, Lawson MF, et al. Delayed intraparenchymal hemorrhage following Pipeline embolization device treatment for a giant recanalized ophthalmic aneurysm. J Neurointerv Surg 2012;4: e24

26. Lopes DK, Johnson AK. Evaluation of cerebral artery perforators and the Pipeline embolization device using optical coherence tomography. J Neurointerv Surg 2012;4:291-94

27. Hampton T, Walsh D, Tolias C, et al. Mural destabilization after aneurysm treatment with a flow-diverting device: a report of two cases. J Neurointerv Surg 2011;3:167-71

28. Fiorella D, Hsu D, Woo HH, et al. Very late thrombosis of a Pipeline embolization device construct: case report. Neurosurgery 2010;67: onsE313-14

29. Crobeddu E, Lanzino G, Kallmes DF, et al. Marked decrease in coil and stent utilization following introduction of flow diversion technology. J Neurointerv Surg 2012 Apr 27. [Epub ahead of print]

30. Siddiqui AH, Kan P, Abla AA, et al. Complications after treatment with Pipeline embolization for giant distal intracranial aneurysms with or without coil embolization. Neurosurgery 2012;71:E509-13

31. Colby GP, Lin LM, Paul AR, et al. Cost comparison of endovascular treatment of anterior circulation aneurysms with the Pipeline embolization device versus stent-assisted coiling. Neurosurgery 2012; 71:944-50

32. Colby GP, Lin LM, Gomez JF, et al. Immediate procedural outcomes in 35 consecutive Pipeline embolization cases: a single-center, single-user experience. J Neurointerv Surg 2012 Mar 29. [Epub ahead of print]

J.L. Brisman Department of Neurosurgery Winthrop University Hospital Mineola, New York

http://dx.doi.org/10.3174/ajnr.A3425 